\title{
Расчет плазмонного резонанса в квазистатическом приближении
}

\author{
А.Е. Веревкин \\ Институт автоматики и электрометрии СО РАН \\ E-mail: novem3094@gmail.com
}

DOI: 10.31868/RFL2020.218

В настоящее время плазмоны - поверхностные электромагнитные волны на границе металла и диэлектрика - нашли применение в различных областях физики: в оптике, биофизике, электронике. При рассеянии волны на наночастицах возбуждается плазмон, что приводит к значительному локальному усилению электромагнитного поля, которое затем можно использовать.

Цель данной работы состоит в нахождении аналитического решения уравнений Максвелла для рассеяния электромагнитной волны на двух параллельных цилиндрах. Если диаметры цилиндров и зазор между ними много меньше длины волны, в нулевом приближении можно перейти от уравнения Гельмгольца к уравнению Лапласа. Для выполнения граничных условий используется конформное преобразование плоскости, приводящее задачу к биполярной системе координат. Найдены решения для различных значений диэлектрической проницаемости и диаметров цилиндров. Получены условия для появления плазмонных резонансов. Проведены сравнения аналитических расчётов с численными методами.

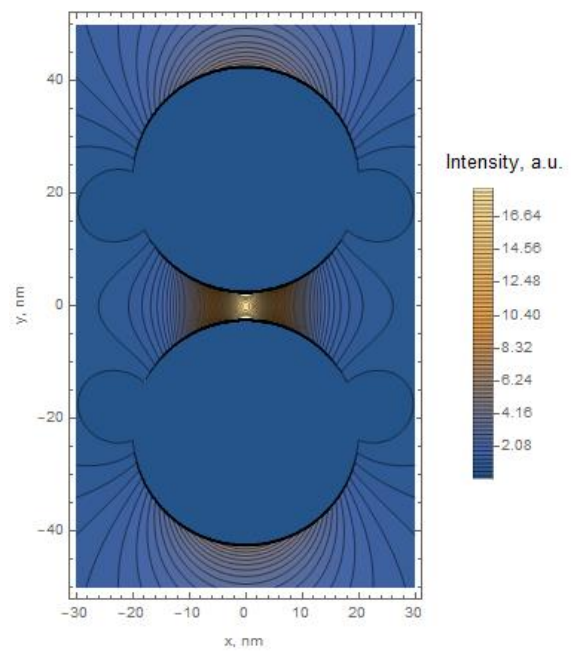

\section{Литература}

[1] P. E. Vorobev. «». Journal of Experimental and Theoretical Physics vol. 110, no. 2, (2010). 